\title{
Hygienebewusstsein weist Lücken auf
}

\author{
Europaweite Studie zeigt falsche Schuldzuweisungen und mangelnde Prävention
}

Der wichtigste Ort, sich eine Lebensmittelvergiftung zu holen, ist zu Hause. Allerdings glaubt die Mehrheit der Österreicher, dass Schule oder Restaurant die Hauptverdächtigen sind. Europaweit steht das Fastfood-Restaurant an oberster Stelle der Verdächtigen. Zu diesen Ergebnissen kommt eine aktuelle Studie des European Hygiene Council, die kürzlich in Wien von Univ.-Doz. Dr. Christoph Wenisch, Vorstand der 4. Med. Abt. im SMZ-Süd - Kaiser Franz Josef Spital präsentiert wurden.

Die Ergebnisse zeigen ein mangelndes Verständnis für die Rolle grundlegender Hygienemaßnahmen im Zusammenhang mit verderblichen Lebensmitteln und der Verbreitung von Grippe und Erkältungen. Die falschen Lebensmittel erhalten die Schuldzuweisung bei Lebensmittelvergiftungen, denn meist sind es die Hände, die die Keime übertragen. Grundsätzlich kann jedes Lebensmittel eine Infektion übertragen, der Großteil der Befragten nimmt aber Fisch und Fleisch an, berichtete Wenisch. Die höchste Sterblichkeit wird bei Salmonellen und Listerien mit 31 respektive 28 Prozent verzeichnet. Die Mehrheit der Umfrageteilnehmer sieht kein Problem darin, rohes Fleisch und Gemüse auf dem gleichen Brett zu schneiden - weil ihnen nicht bewusst ist, dass verschmutzte Oberflächen eine wichtige Rolle bei der Übertragung von Keimen spielen können. Nur 23,8 Prozent der Österreicher wissen auch, dass der Verzehr von rohem Gemüse zu Lebensmittelvergiftungen führen kann. Mehr als ein Drittel der Befragten wusste nicht, dass mangelnde Handhygiene in der Küche oder nach dem Toilettenbesuch Lebensmittelvergiftungen verursachen kann.

\section{Zu Hause bleiben, wenn man erkältet ist}

Dazu kommt ein geringes Bewusstsein für die Übertragungswege von Erkältungsund Grippeerkrankungen, was dazu führt, dass sich nur 56,5 Prozent öfter die Hände waschen, wenn sie selbst erkrankt sind und 47,2 Prozent der Befragten bei einer Erkältung nicht zu Hause bleiben, um eine Ansteckung der Arbeitskollegen zu verhin-

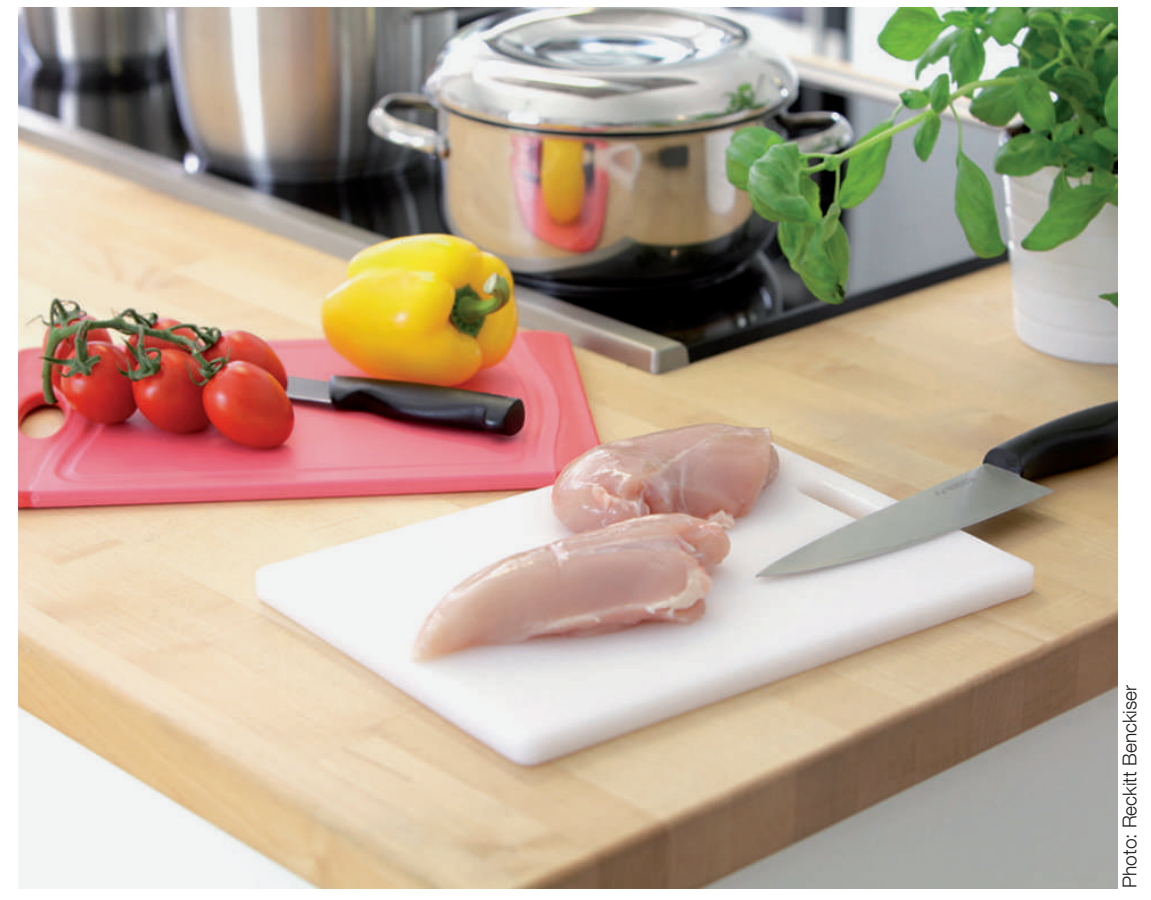

Rohes Fleisch und Gemüse sollten nicht auf dem gleichen Brett geschnitten werden. dern. In Österreich sind es, so Wenisch nur 38 Prozent die daheim bleiben, um eine Verbreitung zu verhindern. Dagegen wäre dies als Sozialverhalten sicher klug, allerdings bewirkt die Angst um den Arbeitsplatz eher das Gegenteil.

Als sinnvolle Maßnahme zusätzlich zur Händedesinfektion nannte Wenisch die Oberflächendesinfektion, denn das Grippevirus überlebt auf unbelebten Oberflächen zwei Tage. Auch dies sei den wenigs- ten der Befragten bewusst. In Österreich glauben 23 Prozent der Befragten, dass ein Influenza-Virus im Haushalt nur eine Stunde überleben kann und nur 17,5 Prozent der Befragten desinfizieren Oberflächen öfter, wenn sie an einer Erkältung oder Grippe leiden.

Quelle: Presseinformation Dettol und European Hygiene Council

\section{Die Europäische Hygiene Studie}

Die Europäische Hygiene Studie dient dazu, den Grad der Achtsamkeit bei Lebensmittelhygiene, Erkältung und Grippe in der europäischen Öffentlichkeit zu untersuchen, und Kenntnisse zu erlangen, wo Wissenslücken in den verschiedenen Regionen bestehen. Die Studie wurde im Auftrag des Hygiene Council von Februar bis März 2012 durchgeführt. Die Daten wurden online von 8.714 Teilnehmern aus 17 europäischen Ländern gesammelt: Österreich, Belgien, Tschechische Republik, Finnland, Frankreich, Deutschland, Griechenland, Irland, Italien, Niederlande, Polen, Portugal, Russland, Spanien, Schweiz, Türkei und Großbritannien. Der Hygiene Council ist eine Initiative, die weltweit führende Experten auf den Gebieten der Mikrobiologie, Virologie, Infektionskrankheiten, Immunologie und öffentlichen Gesundheit zusammenführt. Ziel ist, realistische und praktische Empfehlungen für einfache Hygienemaßnahmen zu formulieren, die der Öffentlichkeit helfen, den Hygienestandard zu Hause und in der Öffentlichkeit zu verbessern und so die Verbreitung von Infektionskrankheiten zu vermindern. 